\title{
Paediatric Inflammatory Bowel Disease and its Relationship with the Microbiome
}

\author{
Rachel S. Fitzgerald ${ }^{1,2}$ (D) Ian R. Sanderson ${ }^{3}$ (D) $\cdot$ Marcus J. Claesson ${ }^{1,2}$ (D)
}

Received: 31 July 2020 / Accepted: 19 January 2021 / Published online: 5 March 2021

(C) The Author(s) 2021

\begin{abstract}
Paediatric inflammatory bowel disease (IBD) is a chronic inflammatory disorder of the digestive tract, comprising of Crohn's disease (CD), ulcerative colitis (UC), and, where classification is undetermined, inflammatory bowel disease unclassified (IBDU). Paediatric IBD incidence is increasing globally, with prevalence highest in the developed world. Though no specific causative agent has been identified for paediatric IBD, it is believed that a number of factors may contribute to the development of the disease, including genetics and the environment. Another potential component in the development of IBD is the microbiota in the digestive tract, particularly the gut. While the exact role that the microbiome plays in IBD is unclear, many studies acknowledge the complex relationship between the gut bacteria and pathogenesis of IBD. In this review, we look at the increasing number of studies investigating the role the microbiome and other biomes play in paediatric patients with IBD, particularly changes associated with IBD, varying disease states, and therapeutics. The paediatric IBD microbiome is significantly different to that of healthy children, with decreased diversity and differences in bacterial composition (such as a decrease in Firmicutes). Changes in the microbiome relating to various treatments of IBD and disease severity have also been observed in multiple studies. Changes in diversity and composition may also extend to other biomes in paediatric IBD, such as the virome and the mycobiome. Research into biome differences in IBD paediatric patients may help progress our understanding of the aetiology of the disease.
\end{abstract}

Keywords Gut microbiota $\cdot$ Microbiome $\cdot$ Paediatric inflammatory bowel disease $\cdot$ Ulcerative colitis $\cdot$ Crohn's disease $\cdot$ Review

\section{Introduction}

Crohn's disease (CD) and ulcerative colitis (UC) are idiopathic inflammatory bowel diseases (IBD). Wilhelm Fabry discovered Crohn's disease in 1623, and its features were more definitively described by T.K. Dalziel in Scotland in 1913 [1] though it was later described by and named Burril B Crohn in 1932. The British physician Sir Samuel Wilks was the first to describe ulcerative colitis in 1859 [2]. Both CD and UC can occur in adults and children. There are a number of proposed risk factors in the development of IBD. One such potential risk factor or perhaps, as some have suggested, even a causative

Marcus J. Claesson

M.Claesson@ucc.ie

School of Microbiology, University College Cork, Cork, Ireland

2 APC Microbiome Ireland, University College Cork, Cork, Ireland

3 Centre for Immunobiology, Blizard Institute, Barts and the London School of Medicine and Dentistry, Queen Mary University of London, London, UK agent, is perturbed microbiota in the intestine. This review will look at the role of the microbiome in paediatric patients with IBD, outlining the findings thus far and the potential future of this particular area of research.

\section{Pathology of Crohn's Disease and Ulcerative Colitis}

\section{Primary Effects}

Although both Crohn's disease (CD) and ulcerative colitis (UC) are chronic inflammatory disorders of the gastrointestinal tract, they have unique features which distinguish them as distinct diseases. UC is a mucosal disease which originates in the rectum and may extend proximally. The ileum is generally not involved, and diffuse inflammation (a microscopic feature of UC) is confined to the mucosa and submucosa [3, 4]. CD shows patchy and segmental distribution and may involve any part of the gastrointestinal tract [3-5], though most commonly 
presents in the ileum. Granulomas and fissures are microscopic features often distinguishing CD from $\mathrm{UC}[3,5]$.

\section{Secondary Effects}

In addition to the gastrointestinal symptoms, IBD is also associated with a set of additional risks. Patients with IBD are at an increased risk of cancer, particularly colon cancer (UC and CD) and small bowel cancer (CD) (for paediatric patients development of such cancers may occur when they reach adulthood). The risk between these intestinal cancers and IBD is influenced by multiple factors, including the extent of the disease, the age of the patient at diagnosis, and the length of time since the patient was diagnosed [5], suggesting the possibility that paediatric patients may be at an even greater risk given the permanency of the diseases. A study of Danish and Finnish paediatric IBD patients found them to be 2.5 times as likely to develop cancer as the general population [6], and similar findings were reported in a study of Swedish paediatric patients by Olen et al. [7]. Patients with IBD may also suffer with extra intestinal manifestations linked to IBD such as arthritis, liver disease, and skin or ocular complications. These manifestations are common in children and adults, but in children, they may precede gastrointestinal symptoms [5].

Paediatric patients are also at risk of growth failure [5], which occurs in approximately $40 \%$ of CD and $10 \%$ of UC paediatric patients [8]. Approximately, a fifth of paediatric CD patients achieved a height significantly less than the expected target ( $>8 \mathrm{~cm}$ below target height) [9]. Consequently, steroids used to treat UC and CD in adults may not always be appropriate in paediatric patients due to the risk of growth retardation associated with these medications, especially in cases of children already suffering malnutrition due to IBD. Malnutrition is a more common occurrence in CD than UC; however, in recent years, an increased number of children diagnosed with IBD are either overweight or obese, following global trends of the general paediatric population [10]. Rates of obesity for children with UC were similar to the general population; however, lower rates were observed in children with CD.

Furthermore, psychosocial stress is often an additional side effect of IBD in children and adults. Absence from school, isolation from peers, extended hospital stays, and familial stress may all be contributing factors to this. Children with IBD were found to be at a higher risk of depressive disorders [11] and more likely to report a lower health related quality of life [12]. Danish and Finnish IBD patients who had childhood onset IBD have been found to be more likely to die from suicide then the general population, which may be reflective of this increased probability of depressive disorders [6].

\section{Incidence and Prevalence of IBD}

Prevalence of CD and UC are highest in the developed world, particularly North America and Europe [13], and the incidence of IBD appears to be increasing, particularly in developing countries [14]. Approximately, 20 to $25 \%$ of patients present with IBD before the age of $20[5,8,15]$, with approximately $4 \%$ of paediatric IBD presenting before the age of 5 , and $10 \%$ before the age of $10[8,15]$. For paediatric IBD, many studies suggest an increasing prevalence of paediatric IBD, even in the developed world [16, 17]. A study of paediatric IBD in Ontario found that prevalence per 100,000 of the population had increased from 42.1 in 1994 to 56.3 in 2005 and incidence rates per 100,000 increased from 9.5 in 1994 to 11.4 in 2005 [18].

\section{Potential Risk Factors for IBD}

A major risk factor influencing the incidence of IBD is its genetic component, with $>200$ IBD associated loci [19]. Familial studies have demonstrated the genetic link of IBD [20], with up to $14 \%$ of IBD patients having a family member also suffering from the disease [21]. These genetic links can be seen in Jewish populations, where both CD and UC are found to more common in people of Jewish descent [2], and familial risk being increased for Jews vs non-Jews [22].

Increased risk is also related to geography with the prevalence and incidence of IBD higher in developed countries though this is most likely due to environmental risk factors such as industrialisation (leading to increases in pollution, such as air pollution [23]), sanitation (the hygiene hypothesis $[24,25])$, and western diet and lifestyle.

A potential risk factor in IBD which has seen increased interest is the role of the microbiota in IBD, particularly the gut microbiota. Studies involving the composition and abundance of microorganisms in the gut (or 'gut microbiome') in IBD have revealed differences between healthy individuals and patients with IBD [26], both in colon [27] and stool samples [28], as well as between different disease states and varying with disease severity [29-31]. These differences can be seen in both children and adult IBD patients; however, for the purpose of this review, the focus will be on paediatric IBD.

\section{The Paediatric Microbiome}

The microorganisms that colonise the human gut are often collectively referred to as the gut microbiome. When a child is born, the gut is initially colonised by environmental microbes, mainly from the mother's microbiome, that may be the vaginal (or faecal) microbiome or the skin microbiome if born via Caesarean section [32]. The phyla Firmicutes, 
Proteobacteria, Bacteroidetes, and the phylum Actinobacteria (especially the genus Bifidobacterium) generally colonise the infant gut $[33,34]$. The two most common phyla in the adult gut, Bacteroidetes and Firmicutes, generally dominate by the end of the first year of the infant's life, though the healthy infant gut continues to undergo dramatic composition changes before stabilising at about age three or four [35]. Most studies agree that the infant gut microbiome closely resembles the adult gut microbiome by about age 3 years [36, 37]. Conversely, some studies argue that there are differences between the adult and child gut microbiome, such as increased abundances of Firmicutes and Actinobacteria observed in children compared to adults [38]. In addition, decreased Bacteroidetes (in pre-adolescent children) [38] and increased numbers of Bifidobacteria were seen in paediatric samples (ages 1-18) [38-40]. Potential differences in the microbiome of healthy children when compared to adults may also suggest that the microbiome of paediatric IBD may potentially differ to adult IBD microbiomes.

\section{The Gut Microbiome in Crohn's Disease and Ulcerative Colitis}

While the exact role the microbiome plays in IBD is unclear, many studies acknowledge the complex relationship between the gut bacteria and pathogenesis of IBD, as reviewed by Wilson and Russell [41]. Various studies have investigated the unique aspects of $\mathrm{CD}$ and $\mathrm{UC}$ in paediatric patients. Increased numbers of Escherichia coli were observed in paediatric CD stool samples but not in UC [42]. Faecalibacterium prausnitzii has been observed to be decreased in paediatric CD stool samples [42, 43] and increased in colonic biopsies [44] of paediatric CD compared to UC and controls. In contrast, Olbjørn and colleagues found only Mycoplasma hominis differed between paediatric CD and UC. Furthermore, the representatives of families Lachnospiraceae and Coriobacteriaceae were observed to be decreased in both paediatric CD and UC compared with controls, as well as the Alistipes species. Many studies have found differences between severe and milder cases of IBD, and others have seen differences between patients pre- and post-treatment. These findings have made it clear that there is a complicated and multifaceted relationship between the disease and the microbiome, though whether the microbiome plays a cause or an effect role, or perhaps a mixture of the two, has yet to be definitively proven.

\section{Changes in IBD from a Healthy Microbiome}

As has also been observed in adult cohorts, children with IBD have a different microbiome than their healthy counterparts. A number of different bacteria have been found to be significantly changed in paediatric IBD patients, compared to controls. Table 1 contains a number of bacteria which have been found to be differentially abundant in paediatric IBD patients when compared with controls, as well as highlighting some of the microbial differences seen between UC and CD, and between varying disease states. Among those found to be decreased in paediatric IBD compared with controls are members of the Bifidobacterium genus [29, 42, 43, 45], which are commonly considered gut commensals and markers of a healthy gut. Specifically, both Bifidobacterium longum and Bifidobacterium pseudocatenulatum were decreased in paediatric IBD patients [45]. Most commonly reduced in paediatric IBD subjects are bacteria from the Firmicutes phylum, including the family Ruminococcaceae, and the genera Eubacterium and Clostridium [29, 42, 43, 45, 46], consistent with findings in adult IBD [47].

Although many studies do report similar findings in terms of which bacterial changes are seen, there are a small number of cases where findings differ across studies. For example, Ruminococcaceae is generally reported as reduced in IBD subjects [45, 48] but in Assa et al., an increase was seen in those with IBD [49]. Of course, inter-study variation may partially be a result of differences between the study designs, such as differences in DNA extraction methods, sequencing, analysis, and of course the type of sample, be that a stool sample or a biopsy (from varying locations) [50]. Moreover, a large inter-continental study of adult IBD recently highlighted geographical changes, in terms of different lifestyle, diet and ethnicity, to account for much of the observed microbiota heterogeneity [31].

Although a reduction in microorganisms considered 'beneficial' is the most striking difference of the microbiome in paediatric IBD, other species appear to colonise the paediatric IBD gut microbiome. Escherichia coli has often found to be increased in paediatric IBD vs controls [42, 46, 51]. Interestingly, a number of studies have found bacteria typical of the oral microbiome to be increased in paediatric IBD vs controls, and in cases of severe vs mild IBD in children [29, 30, 48]. There is speculation that these species may be taking advantage of the changed environment, or potentially exasperating or driving (by inducing $T$ helper cells) inflammation in the guts of patients with IBD $[30,52,53]$. Many of these bacteria are anaerobic, such as Veillonellaceae and Fusobacterium, or facultative anaerobes, such as Haemophilus parainfluenzae, a member of the Pasteurellaceae family.

\section{Disease States and Severity in Paediatric IBD}

Variation in microbial composition can also be seen across disease states and varying with disease severity, where the gut microbiome of children with mild IBD appears closer to healthy microbiome than for more severe IBD cases. Disease 

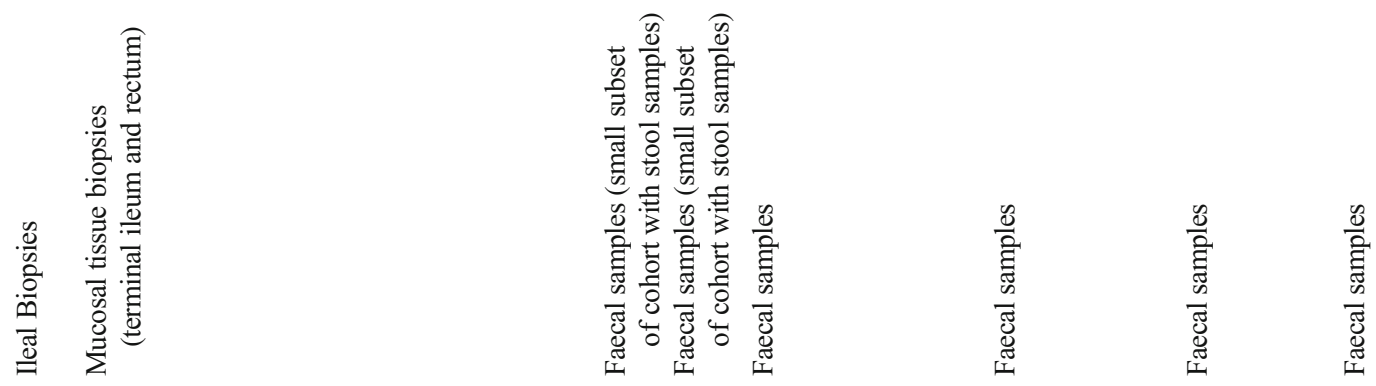

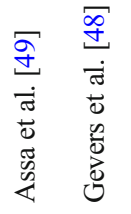

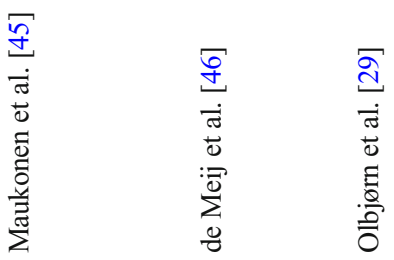

已
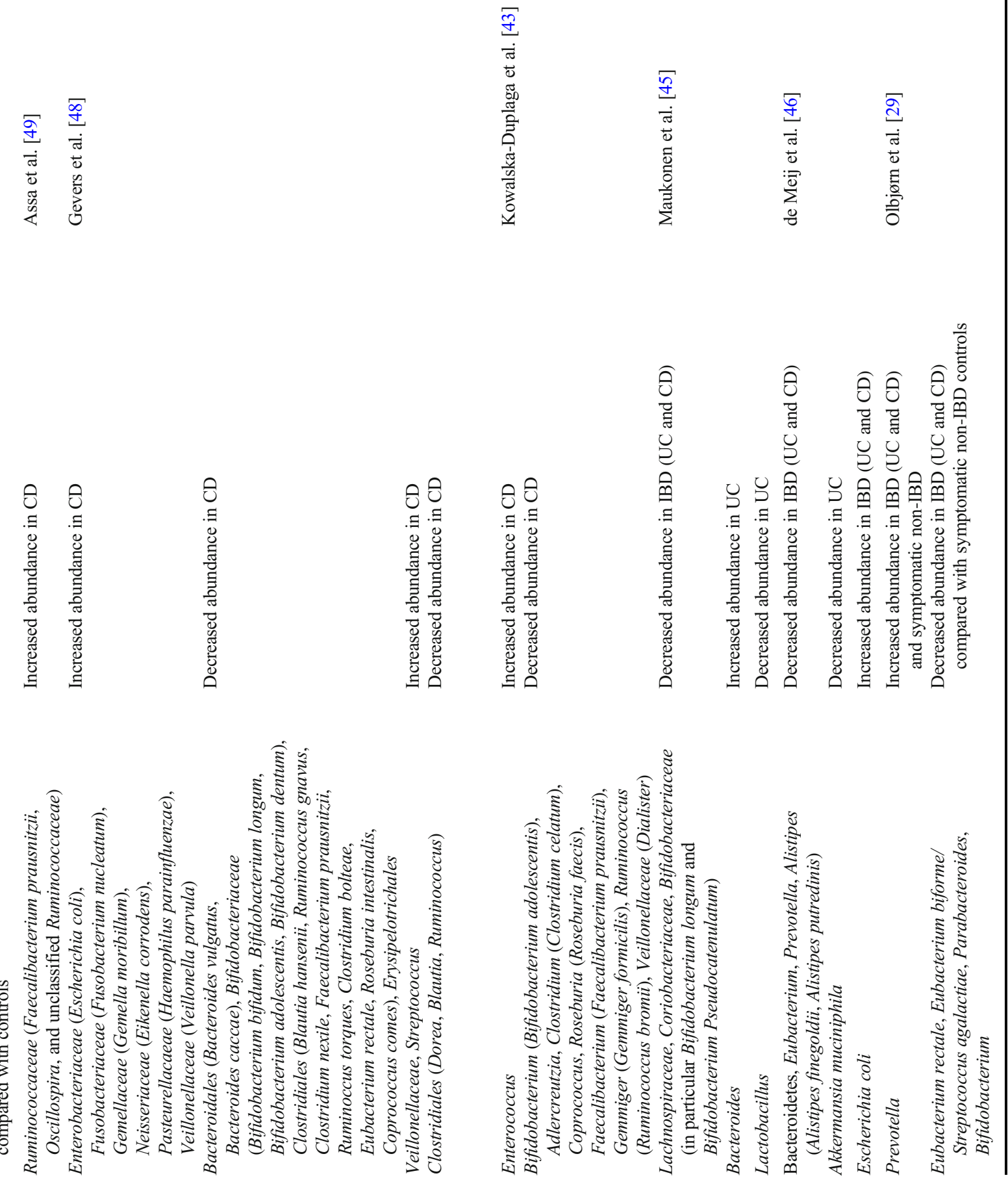


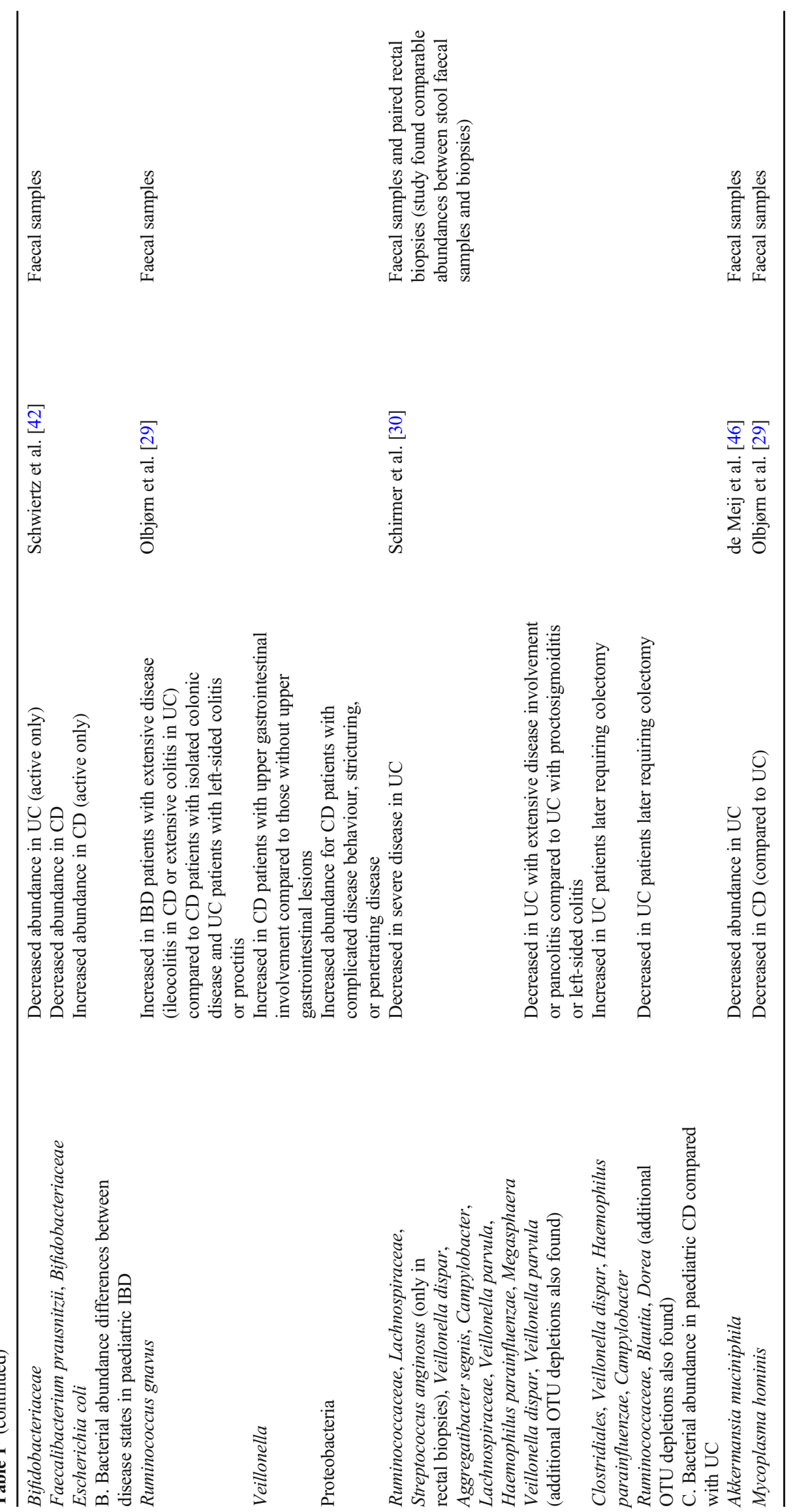


severity is often evaluating using specific scoring metrics such as the Paediatric Crohn's Disease Activity Index (PCDAI) [54], the Mayo score [55], and the Paediatric Ulcerative Colitis Activity Index (PUCAI) [56]. These scoring systems generally take into account the impact of the disease on the patient, the disease burden, and disease course [57]. For instance, Ruminococcus gnavus, a gut coccus with a potential inflammatory role [58], was increased in children with total or ileocolitis compared to those with colonic CD or left-sided UC [29]. This taxa was also particularly enriched in the guts of paediatric IBD patients with increased disease activity [59]. Henke and co-authors proposed that this may be a result of a glucorhamnan polysaccharide synthesised and secreted by Ruminococcus gnavus, thereby promoting inflammation through the induced secretion of TNFalpha, which is dependent on the toll-like receptor 4 (TLR4) [58].

Furthermore, Veillonella was increased in paediatric CD patients who had upper gastro manifestations [29]. Specific strains of these, Veillonella dispar and Veillonella parvula, as well as other oral cavity bacteria such as Haemophilus parainfluenzae, were also found to be increased in severe disease [30]. Interestingly, Haemophilus parainfluenzae was detected at high levels in severe UC disease with drastic reductions over treatment time, and appeared to correlate with paediatric patients who would then enter remission. However, children with mild disease and less but consistent abundance of Haemophilus parainfluenzae were less likely to enter remission. Schirmer and colleagues hypothesised that this may mean a decrease in certain key bacteria, such as Haemophilus parainfluenzae, which may positively influence disease outcome.

\section{Potential Microbiome-Related Therapeutics, Diagnostics, and Prognostics}

Although there is no cure available for $\mathrm{CD}$ or $\mathrm{UC}$, a number of treatments are available for inducing remission. These treatment options vary depending on disease severity and disease type, and often have a significant effect on the microbiome. For mild to moderate IBD, 5-aminosalicylic acid (5-ASA) or antibiotic therapy have been used to induce remission [5], which in some studies appears to affect the gut microbiome [30]. The same authors also implicated several bacterial taxa, previously associated with disease severity, with antibiotic usage in paediatric UC patients [30]. These results were echoed in a previous study on paediatric $\mathrm{CD}$ that found antibiotic usage to increase microbiome dysbiosis in $\mathrm{CD}$ [48]. Antibiotic usage was also associated with both bacterial and fungal dysbiosis in a cohort of paediatric CD patients by Lewis et al. [60]. These findings, along with studies examining antibiotics as potential causative agents in the general paediatric population [61] and observational studies linking antibiotic usage in children to an increased risk of developing IBD $[62,63]$, highlights the need for further study of the longterm effects on paediatric IBD gut post-antibiotic-induced remission.

Corticosteroids, biologic therapy (anti-TNF agents such as infliximab, often for non-responders to traditional treatments), and thiopurines are used to treat children with $\mathrm{UC}$ and $\mathrm{CD}$ for moderate to severe disease [5]. Steroid treatment, however, comes with additional risk for paediatric patients, as it is imperative to avoid stunting growth in children who may already be at risk of growth retardation due to malnutrition, particularly patients with $\mathrm{CD}$. Schirmer and colleagues also found 47 taxa associated with corticosteroids, whereof a majority were correlated with both remission and non-remission groups, raising the question of whether these changes in microbial composition are a by-product of treatment, or a driving factor in the efficacy of the treatment of IBD [30]. The interaction between biological therapies, such as anti-TNF, and the microbiome has not been extensively documented in paediatric IBD patients. However, Firmicutes and Mycoplasma hominis were decreased in paediatric IBD patients treated with biologic therapy compared with conventional methods (EEN in $\mathrm{CD}$, and steroids and 5-ASA in CD and UC) [29]. No reduction in fungal colonisation in paediatric $\mathrm{CD}$ following treatment with anti-TNF has been observed [60].

In addition to medication-based treatments, both diet interventions and surgery are commonly used in the treatment of IBD. Special diets are found to help in CD, such as exclusive enteral nutrition (EEN), partial enteral nutrition (PEN) with a free diet, and CD exclusion diets (CDED). In Europe, EEN is currently recommended as first-line treatment for new cases [64]. These diets can have a profound effect on the microbiome, and microbial changes associated with treatment diets have been found in a multitude of IBD studies. Lewis and co-authors found that the microbiome composition of paediatric CD patients who responded to EEN was more similar to healthy controls than those who did not respond to EEN treatment. The authors also observed decreased fungal colonisation after EEN treatment [60] and Haemophilus species (associated with disease severity in paediatric UC [30]). The genus Alistipes was further increased in children receiving EEN but negatively associated with antibiotic treatment. In particular, Alistipes finegoldiii and Alistipes putredinus were decreased in paediatric CD patients, but these increased with EEN treatment (EEN was only given to CD patients) [46]. Escherichia coli has also been reported to be negatively associated with EEN treatment, indicating a shift towards a more 'healthy' microbiome with this treatment [46]. The authors also observed these trends in UC patients, who were treated with either aminosalicylates or aminosalicylates and corticosteroids. It is worth noting that those on EEN in this study were also receiving thiopurines [46]. In contrast, Quince and colleagues found that the microbiota did not return to that seen 
in healthy controls after successful treatment of CD with EEN, but to a distinct state [65].

Although EEN is an effective treatment for $\mathrm{CD}$ in paediatric patients (especially those with mild to moderate disease), one major shortcoming of the treatment is implementation due to low tolerance of the diet. Due to the challenges of maintaining a liquid diet for the time required, as well as a possible reversion seen when returning to a 'free' diet, a recently proposed treatment regimen is a so-called CD exclusion diet (CDED), which involves a whole food diet combined with partial enteral nutrition (PEN). Levine and colleagues reported that EEN and CDED resulted in similar levels of remission achievement at week 6 of a 12-week study, but CDED was more likely to have sustained remission at week 12 [66]. Similar species alterations were observed in the two treatment groups at week 6 (decreases in Proteobacteria, Haemophilus, Veillonella (which may be linked to lactate presence as these are lactate-utilising bacteria), Bifidobacterium, Prevotella, and Anaerostipes and increases in Oscillibacter and Roseburia). However, at week 12, those on EEN appeared to rebound to pre-treatment levels. These divergences once EEN patients began to transition back to a free diet suggest that CDED may be a more sustainable treatment strategy for paediatric $\mathrm{CD}$ [66]. Another study investigating $\mathrm{CD}$ exclusion diets in IBD had similar findings regarding achieving remission in EEN and CDED in adult CD subjects and a small number of paediatric $C D$ subjects [67].

Surgery is often a treatment option of last resort for refractory disease. Twenty-one OTUs (operational taxonomic unit, represents a taxonomic unit of a bacterial species or genus, clustered by sequence similarity) were associated a colectomy being required in later treatment for paediatric UC patients, and three of the OTUs that were increased were oral bacteria, which were also associated with severe disease. Twelve of those decreased were also depleted in those with severe disease [30]. Higher abundances of Proteobacteria and lower Faecalibacterium prausnitzii were found to be associated with surgery and a lack of mucosal healing in paediatric IBD [29]. Decreased levels Faecalibacterium prausnitzii have also been observed in resected adult IBD patients [31]. The findings in these studies may suggest that certain bacteria could be used as identifying markers in patients who would become medical non-responders at a later point.

Faecal microbiota transplantation (FMT) may also be a potential treatment option for paediatric IBD, though it is currently not widely utilised [68]. Adult IBD studies (CD and UC) have shown success using FMT, with some patients achieving remission or showing a clinical response $[69,70]$. Although a smaller number of studies are available for paediatric $\mathrm{CD}$ and $\mathrm{UC}$, there has been some therapeutic potential suggested [71, 72]. However, other studies found that although safe, FMT did not provide any clinical benefit for some patients (adult mild to moderate UC [70], and paediatric UC [73]).

\section{The Virome}

The viruses in the gut (the gut virome) have not been studied to the same degree as the bacteria in the gut, including those studies targeting IBD. However, it has been suggested that different abundances in the bacteriophages in the gut may also play a role in IBD [74]. The viral taxa found to be most abundant in the gut of both children and adults, irrespective of disease status, were Caudovirales and Microviridae [74, 75]. Increased richness and diversity of Caudovirales was observed in adult IBD compared with controls [74], and increased Caudovirales abundance has been reported in paediatric CD compared with UC [75]. This increase in Caudovirales was not detected in paediatric CD compared with healthy controls [60]. While increased richness of Microviridae in controls was observed compared to paediatric $\mathrm{CD}$ [75], this was not replicated in a more recent study, where no increased richness in adult $\mathrm{UC}$ or $\mathrm{CD}$ was seen when compared to controls [76]. The authors did however report increased diversity of Caudovirales in $\mathrm{CD}$ patients, but this was not seen in UC. Here, a significantly increased number of temperature phages in $\mathrm{CD}$ when compared with healthy controls [76].

\section{Mycobiome}

The fungal microbiota, or mycobiome, though also less investigated than the bacterial microbiota, may show differences in the IBD gut when compared with healthy individuals. While several number of studies have observed changes in the fungal profile of IBD patients compared to healthy controls $[60,77,78]$, these changes are not uniform between studies. An increased fungal abundance overall was observed in paediatric CD [60], and an increased fungal biodiversity was reported in $\mathrm{CD}$, but not UC [77]. In contrast, Chehoud and colleagues reported reduced fungal diversity in paediatric IBD [79]. An adult cohort [77] and a small paediatric cohort [78] both reported Basidiomycota to be more abundant in IBD, with a corresponding decrease in Ascomycota. Malassezia (primarily Malassezia restricta) was found to be associated with $\mathrm{CD}$, and responsible for the increase in basidiomycetes seen in the Limon et al. cohort of adult CD patients. Malassezia restricta was linked to adult CD patients with a disease-linked polymorphism in CARD9, and was found to exacerbate colitis in mouse models [80]. However, another study found fungi from the Ascomycota phylum to be increased in paediatric CD [60], as well as Candida albicans, which was also increased in adult IBD [77]. Another taxa, Cyberlindnera jadinii, was increased in paediatric IBD compared with controls [60, 79]. 


\section{Oral Microbiome}

Though UC is generally limited to the colon, CD can occur anywhere in the gastrointestinal tract, and can include involvement of the oral cavity, with approximately $40 \%$ of a cohort of Irish paediatric $\mathrm{CD}$ patients (over a 3 year period) having oral involvement [81]. A significant decrease in diversity was seen in tongue samples of paediatric $\mathrm{CD}$ patients when compared to healthy and though non-significant, a decrease was also seen in the buccal samples of these paediatric CD patients [82]. Tongue samples in $\mathrm{CD}$ also showed a decrease in Fusobacteria and Firmicutes, but no phylum changes were observed in the buccal samples [82]. No difference in diversity was observed in UC patients in the tongue or buccal samples when compared with healthy, but certain bacterial changes were observed in tongue samples, namely a decrease in Fusobacteria and increased levels of Spirochaetes, Synergistetes, and Bacteroidetes [82]. As previously mentioned, increased numbers of oral bacteria have been observed in the gut of IBD vs healthy individuals, and in IBD patients with increased disease severity. This could suggest that an invasion of oral bacteria to the gut may contribute to part of the dysbiosis observed.

\section{Conclusion}

Paediatric IBD is a lifelong condition (currently with no medical cure) and can have a severe impact on the quality of life of those suffering from the disease. The incidence and prevalence of paediatric IBD is rising, for both $\mathrm{CD}$ and UC, and the prevalence is particularly high in industrialised countries. The aetiology of IBD is unknown though it is thought that there is a genetic element, as well as environmental risks, such as industrialisation, and a western lifestyle. The microbiome is also believed to contribute to the risk of developing IBD.

Studies have also shown that both CD and UC have microbiomes that are significantly different from healthy individuals and it is clear from the literature that the microbiome and IBD have a varied and complex relationship. There is some disagreement on whether the healthy paediatric microbiome is identical to the adult microbiome, with arguments on both sides. However, both adult and paediatric IBD exhibit significant differences between disease and healthy controls. There is a decrease in bacterial diversity seen in the guts of IBD patients compared to controls. A number of bacteria, particularly commensals, have been reduced in paediatric IBD compared with controls, such as the Bifidobacterium genus and those in the Firmicutes phylum, such as those from the genera Eubacterium, Ruminococcaceae, and Clostridium. Escherichia coli and various oral bacteria, such as Veillonellaceae, Fusobacterium, and Haemophilus parainfluenzae appear to be increased in paediatric IBD.
Significant differences in microbial composition are evident in the different disease states and disease severity levels, like oral cavity bacteria (such as Haemophilus parainfluenzae) which were found to be increased with disease severity. Possible future research in this area may focus on whether the bacterial changes seen with increased disease severity are an outcome of the worsening disease or if the bacteria have the potential to be contributing to the changes in disease state or severity.

Treatments for IBD appear to have at least some impact on the microbiome, whether that is an intentional effect or a byproduct of treatment. Antibiotics have been found to increase dysbiosis in both paediatric $\mathrm{CD}$ and $\mathrm{UC}$, and microbes associated with disease severity have also been linked to antibiotic usage by studies. Both 5-ASAs and corticosteroids have been linked to changes in the microbiome and biological therapies such as anti-TNF may be linked to decreases in Firmicutes. Diet therapy, such as EEN, is extensively used as a treatment in paediatric CD. EEN was found to move paediatric CD patients closer to a healthy control microbiome in some studies, but to a distinct pattern of microbiota in others, and some bacteria were also reported to be changed with EEN therapy. An emerging diet therapy, CDED, was found to have similar microbiome changes as EEN treatment (such as Proteobacteria decreases). The CDED study shows promise for dietary treatments in paediatric patients without resorting to an entirely enteral diet.

Investigation of the oral microbiome is also worth considering as up to $40 \%$ of paediatric CD patients in one study had oral involvement. Decreases in diversity were found in tongue samples from paediatric $\mathrm{CD}$, and both $\mathrm{CD}$ and $\mathrm{UC}$ had decreased Fusobacteria in tongue samples when compared to controls. Given the number of studies identifying oral bacteria in the gut of paediatric IBD patients, research into whether the oral bacteria may be invading the gut and contributing to the dysbiosis observed may be a future area of interest.

Less well studied, but a potential future area of interest are the other gut biomes in IBD: the virome and the mycobiome. The virome in IBD is a relatively unexplored area of research, and some disparity exists between the results so far, such as the possibility of increased Caudovirales in IBD. Though currently not extensively explored, a number of studies suggest that there may be significant changes in the mycobiome of IBD patients, and that fungal microbes may be more abundant in CD. Increased Basidiomycota has been reported in paediatric IBD patients, as well as increased abundances of species such as Cyberlindnera jadinii and Candida albicans.

Research into the paediatric IBD microbiome over the last number of years has yielded a large amount of new knowledge about the role microorganisms may play in the aetiology and pathology of $\mathrm{CD}$ and UC. These studies have great clinical significance and the accumulation of this knowledge is essential to gain a deeper understanding of the development and 
mechanisms of these serious conditions, as well as being crucial for the development of advancements in the treatment options for CD and UC.

Funding Irish Research Council (grant number GOIPG/2017/1573)

Crohn's and Colitis Foundation (grant number 510264)

Science Foundation Ireland (grant number SFI/12/RC/2273_P2)

Open Access This article is licensed under a Creative Commons Attribution 4.0 International License, which permits use, sharing, adaptation, distribution and reproduction in any medium or format, as long as you give appropriate credit to the original author(s) and the source, provide a link to the Creative Commons licence, and indicate if changes were made. The images or other third party material in this article are included in the article's Creative Commons licence, unless indicated otherwise in a credit line to the material. If material is not included in the article's Creative Commons licence and your intended use is not permitted by statutory regulation or exceeds the permitted use, you will need to obtain permission directly from the copyright holder. To view a copy of this licence, visit http://creativecommons.org/licenses/by/4.0/.

\section{References}

1. Dalziel TK (1913) Chronic interstitial enteritis. Br Med J 2:10681070

2. Baumgart DC, Carding SR (2007) Inflammatory bowel disease: cause and immunobiology. Lancet (London, England) 369:16271640. https://doi.org/10.1016/s0140-6736(07)60750-8

3. Geboes K (2008) What histologic features best differentiate Crohn's disease from ulcerative colitis? Inflamm Bowel Dis 14(Suppl 2):S168-S169. https://doi.org/10.1002/ibd.20598

4. Xavier RJ, Podolsky DK (2007) Unravelling the pathogenesis of inflammatory bowel disease. Nature 448:427-434

5. Diefenbach KA, Breuer CK (2006) Pediatric inflammatory bowel disease. World J Gastroenterol 12:3204-3212. https://doi.org/10. 3748/wjg.v12.i20.3204

6. Malham M, Jakobsen C, Paerregaard A, Virta LJ, Kolho K-L, Wewer V (2019) The incidence of cancer and mortality in paediatric onset inflammatory bowel disease in Denmark and Finland during a 23-year period: a population-based study. Aliment Pharmacol Ther 50:33-39. https://doi.org/10.1111/apt.15258

7. Olén O, Askling J, Sachs M, Frumento P, Neovius M, Smedby K, Ekbom A, Malmborg P, Ludvigsson J (2017) Childhood onset inflammatory bowel disease and risk of cancer: a Swedish nationwide cohort study 1964-2014. BMJ 358:j3951. https://doi.org/10. 1136/bmj.j3951

8. Rosen MJ, Dhawan A, Saeed SA (2015) Inflammatory bowel disease in children and adolescents. JAMA Pediatr 169:1053-1060. https://doi.org/10.1001/jamapediatrics.2015.1982

9. Sawczenko A, Ballinger AB, Savage MO, Sanderson IR (2006) Clinical features affecting final adult height in patients with pediatric-onset Crohn's disease. Pediatrics 118:124-129. https:// doi.org/10.1542/peds.2005-2931

10. Long MD, Crandall WV, Leibowitz IH, Duffy L, del Rosario F, Kim SC, Integlia MJ, Berman J, Grunow J, Colletti RB, Schoen BT, Patel AS, Baron H, Israel E, Russell G, Ali S, Herfarth HH, Martin C, Kappelman MD (2011) Prevalence and epidemiology of overweight and obesity in children with inflammatory bowel disease. Inflamm Bowel Dis 17:2162-2168. https://doi.org/10.1002/ ibd. 21585
11. Greenley RN, Hommel KA, Nebel J, Raboin T, Li SH, Simpson P, Mackner L (2010) A meta-analytic review of the psychosocial adjustment of youth with inflammatory bowel disease. J Pediatr Psychol 35:857-869. https://doi.org/10.1093/jpepsy/jsp120

12. Ross SC, Strachan J, Russell RK, Wilson SL (2011) Psychosocial functioning and health-related quality of life in paediatric inflammatory bowel disease. J Pediatr Gastroenterol Nutr 53:480-488. https://doi.org/10.1097/MPG.0b013e31822f2c32

13. Ng SC, Shi HY, Hamidi N, Underwood FE, Tang W, Benchimol EI, Panaccione R, Ghosh S, Wu JCY, Chan FKL, Sung JJY, Kaplan GG (2018) Worldwide incidence and prevalence of inflammatory bowel disease in the 21 st century: a systematic review of population-based studies. Lancet (London, England) 390:2769 2778. https://doi.org/10.1016/s0140-6736(17)32448-0

14. Molodecky NA, Soon IS, Rabi DM, Ghali WA, Ferris M, Chernoff G, Benchimol EI, Panaccione R, Ghosh S, Barkema HW, Kaplan GG (2012) Increasing incidence and prevalence of the inflammatory bowel diseases with time, based on systematic review. Gastroenterology 142:46-54.e42; quiz e30. https://doi.org/10. 1053/j.gastro.2011.10.001

15. Kelsen J, Baldassano RN (2008) Inflammatory bowel disease: the difference between children and adults. Inflamm Bowel Dis 14:S9S11. https://doi.org/10.1002/ibd.20560

16. Benchimol EI, Fortinsky KJ, Gozdyra P, Van den Heuvel M, Van Limbergen J, Griffiths AM (2011) Epidemiology of pediatric inflammatory bowel disease: a systematic review of international trends. Inflamm Bowel Dis 17:423-439. https://doi.org/10.1002/ ibd.21349

17. Hope B, Shahdadpuri R, Dunne C, Broderick AM, Grant T, Hamzawi M, Driscoll K, Quinn S, Hussey S, Bourke B (2012) Rapid rise in incidence of Irish paediatric inflammatory bowel disease. Arch Dis Child 97:590-594. https://doi.org/10.1136/ archdischild-2011-300651

18. Benchimol EI, Guttmann A, Griffiths AM, Rabeneck L, Mack DR, Brill H, Howard J, Guan J, To T (2009) Increasing incidence of paediatric inflammatory bowel disease in Ontario, Canada: evidence from health administrative data. Gut 58:1490-1497. https:// doi.org/10.1136/gut.2009.188383

19. Schirmer M, Garner A, Vlamakis H, Xavier RJ (2019) Microbial genes and pathways in inflammatory bowel disease. Nat Rev Microbiol 17:497-511. https://doi.org/10.1038/s41579-019-02136

20. Van Limbergen J, Radford-Smith G, Satsangi J (2014) Advances in IBD genetics. Nat Rev Gastroenterol Hepatol 11:372-385. https:// doi.org/10.1038/nrgastro.2014.27

21. Ananthakrishnan AN (2015) Epidemiology and risk factors for IBD. Nat Rev Gastroenterol Hepatol 12:205-217. https://doi.org/ 10.1038/nrgastro.2015.34

22. Yang H, McElree C, Roth MP, Shanahan F, Targan SR, Rotter JI (1993) Familial empirical risks for inflammatory bowel disease: differences between Jews and non-Jews. Gut 34:517-524. https:// doi.org/10.1136/gut.34.4.517

23. Ananthakrishnan AN, McGinley EL, Binion DG, Saeian K (2010) Ambient air pollution correlates with hospitalizations for inflammatory bowel disease: an ecologic analysis. Inflamm Bowel Dis 17: 1138-1145. https://doi.org/10.1002/ibd.21455

24. Koloski N-A, Bret L, Radford-Smith G (2008) Hygiene hypothesis in inflammatory bowel disease: a critical review of the literature. World J Gastroenterol 14:165-173. https://doi.org/10.3748/wjg.14. 165

25. López-Serrano P, Pérez-Calle JL, Pérez-Fernández MT, FernándezFont JM, Boixeda de Miguel D, Fernández-Rodríguez CM (2010) Environmental risk factors in inflammatory bowel diseases. Investigating the hygiene hypothesis: a Spanish case-control study. Scand J Gastroenterol 45:1464-1471. https://doi.org/10.3109/ 00365521.2010.510575 
26. Lloyd-Price J, Arze C, Ananthakrishnan AN, Schirmer M, AvilaPacheco J, Poon TW, Andrews E, Ajami NJ, Bonham KS, Brislawn CJ, Casero D, Courtney H, Gonzalez A, Graeber TG, Hall AB, Lake K, Landers CJ, Mallick H, Plichta DR, Prasad M, Rahnavard G, Sauk J, Shungin D, Vázquez-Baeza Y, White RA, Bishai J, Bullock K, Deik A, Dennis C, Kaplan JL, Khalili H, McIver LJ, Moran CJ, Nguyen L, Pierce KA, Schwager R, SirotaMadi A, Stevens BW, Tan W, ten Hoeve JJ, Weingart G, Wilson RG, Yajnik V, Braun J, Denson LA, Jansson JK, Knight R, Kugathasan S, McGovern DPB, Petrosino JF, Stappenbeck TS, Winter HS, Clish CB, Franzosa EA, Vlamakis H, Xavier RJ, Huttenhower C, Investigators I (2019) Multi-omics of the gut microbial ecosystem in inflammatory bowel diseases. Nature 569: 655-662. https://doi.org/10.1038/s41586-019-1237-9

27. Ryan FJ, Ahern AM, Fitzgerald RS, Laserna-Mendieta EJ, Power EM, Clooney AG, O’Donoghue KW, McMurdie PJ, Iwai S, CritsChristoph A, Sheehan D, Moran C, Flemer B, Zomer AL, Fanning A, O'Callaghan J, Walton J, Temko A, Stack W, Jackson L, Joyce SA, Melgar S, DeSantis TZ, Bell JT, Shanahan F, Claesson MJ (2020) Colonic microbiota is associated with inflammation and host epigenomic alterations in inflammatory bowel disease. Nat Commun 11:1512. https://doi.org/10.1038/s41467-020-15342-5

28. Halfvarson J, Brislawn CJ, Lamendella R, Vázquez-Baeza Y, Walters WA, Bramer LM, D'Amato M, Bonfiglio F, McDonald D, Gonzalez A, McClure EE, Dunklebarger MF, Knight R, Jansson JK (2017) Dynamics of the human gut microbiome in inflammatory bowel disease. Nat Microbiol 2:17004. https://doi.org/10.1038/ nmicrobiol.2017.4

29. Olbjørn C, Cvancarova Småstuen M, Thiis-Evensen E, Nakstad B, Vatn MH, Jahnsen J, Ricanek P, Vatn S, Moen AEF, Tannæs TM, Lindstrøm JC, Söderholm JD, Halfvarson J, Gomollón F, Casén C, Karlsson MK, Kalla R, Adams AT, Satsangi J, Perminow G (2019) Fecal microbiota profiles in treatment-naïve pediatric inflammatory bowel disease - associations with disease phenotype, treatment, and outcome. Clin Exp Gastroenterol 12:37-49. https://doi.org/10. 2147/ceg.s186235

30. Schirmer M, Denson L, Vlamakis H, Franzosa EA, Thomas S, Gotman NM, Rufo P, Baker SS, Sauer C, Markowitz J, Pfefferkorn M, Oliva-Hemker M, Rosh J, Otley A, Boyle B, Mack D, Baldassano R, Keljo D, LeLeiko N, Heyman M, Griffiths A, Patel AS, Noe J, Kugathasan S, Walters T, Huttenhower C, Hyams J, Xavier RJ (2018) Compositional and temporal changes in the gut microbiome of pediatric ulcerative colitis patients are linked to disease course. Cell Host Microbe 24: 600-610.e604. https://doi.org/10.1016/j.chom.2018.09.009

31. Clooney AG, Eckenberger J, Laserna-Mendieta E, Sexton KA, Bernstein MT, Vagianos K, Sargent M, Ryan FJ, Moran C, Sheehan D, Sleator RD, Targownik LE, Bernstein CN, Shanahan F, Claesson MJ (2020) Ranking microbiome variance in inflammatory bowel disease: a large longitudinal intercontinental study. Gut.: gutjnl-2020-321106. https://doi.org/10.1136/gutjnl-2020-321106

32. Mueller NT, Bakacs E, Combellick J, Grigoryan Z, DominguezBello MG (2015) The infant microbiome development: mom matters. Trends Mol Med 21:109-117. https://doi.org/10.1016/j. molmed.2014.12.002

33. Houghteling PD, Walker WA (2015) Why is initial bacterial colonization of the intestine important to infants' and children's health? J Pediatr Gastroenterol Nutr 60:294-307

34. Jakobsson HE, Abrahamsson TR, Jenmalm MC, Harris K, Quince C, Jernberg C, Björkstén B, Engstrand L, Andersson AF (2014) Decreased gut microbiota diversity, delayed Bacteroidetes colonisation and reduced Th1 responses in infants delivered by Caesarean section. Gut 63:559-566. https://doi.org/10.1136/gutjnl-2012303249

35. Fouhy F, Watkins C, Hill CJ, O'Shea C-A, Nagle B, Dempsey EM, O’Toole PW, Ross RP, Ryan CA, Stanton C (2019) Perinatal factors affect the gut microbiota up to four years after birth. Nat Commun 10:1517-1517. https://doi.org/10.1038/s41467-01909252-4

36. Yatsunenko T, Rey FE, Manary MJ, Trehan I, Dominguez-Bello MG, Contreras M, Magris M, Hidalgo G, Baldassano RN, Anokhin AP, Heath AC, Warner B, Reeder J, Kuczynski J, Caporaso JG, Lozupone CA, Lauber C, Clemente JC, Knights D, Knight R, Gordon JI (2012) Human gut microbiome viewed across age and geography. Nature 486:222-227. https://doi.org/10.1038/ nature11053

37. Koenig JE, Spor A, Scalfone N, Fricker AD, Stombaugh J, Knight R, Angenent LT, Ley RE (2011) Succession of microbial consortia in the developing infant gut microbiome. Proc Natl Acad Sci 108: 4578-4585. https://doi.org/10.1073/pnas. 1000081107

38. Hollister EB, Riehle K, Luna RA, Weidler EM, Rubio-Gonzales M, Mistretta TA, Raza S, Doddapaneni HV, Metcalf GA, Muzny DM, Gibbs RA, Petrosino JF, Shulman RJ, Versalovic J (2015) Structure and function of the healthy pre-adolescent pediatric gut microbiome. Microbiome 3:36. https://doi.org/10.1186/s40168015-0101-x

39. Agans R, Rigsbee L, Kenche H, Michail S, Khamis HJ, Paliy O (2011) Distal gut microbiota of adolescent children is different from that of adults. FEMS Microbiol Ecol 77:404-412. https://doi.org/ 10.1111/j.1574-6941.2011.01120.x

40. Ringel-Kulka T, Cheng J, Ringel Y, Salojärvi J, Carroll I, Palva A, de Vos WM, Satokari R (2013) Intestinal microbiota in healthy U.S. young children and adults-a high throughput microarray analysis. PLoS One 8:e64315. https://doi.org/10.1371/journal.pone. 0064315

41. Wilson DC, Russell RK (2017) Overview of paediatric IBD. Semin Pediatr Surg 26:344-348. https://doi.org/10.1053/j.sempedsurg. 2017.10.002

42. Schwiertz A, Jacobi M, Frick JS, Richter M, Rusch K, Köhler H (2010) Microbiota in pediatric inflammatory bowel disease. J Pediatr 157:240-244.e241. https://doi.org/10.1016/j.jpeds.2010. 02.046

43. Kowalska-Duplaga K, Gosiewski T, Kapusta P, Sroka-Oleksiak A, Wędrychowicz A, Pieczarkowski S, Ludwig-Słomczyńska AH, Wołkow PP, Fyderek K (2019) Differences in the intestinal microbiome of healthy children and patients with newly diagnosed Crohn's disease. Sci Rep 9:18880. https://doi.org/10.1038/s41598019-55290-9

44. Hansen R, Russell RK, Reiff C, Louis P, McIntosh F, Berry SH, Mukhopadhya I, Bisset WM, Barclay AR, Bishop J, Flynn DM, McGrogan P, Loganathan S, Mahdi G, Flint HJ, El-Omar EM, Hold GL (2012) Microbiota of de-novo pediatric IBD: increased Faecalibacterium prausnitzii and reduced bacterial diversity in Crohn's but not in ulcerative colitis. Am J Gastroenterol 107: 1913-1922. https://doi.org/10.1038/ajg.2012.335

45. Maukonen J, Kolho KL, Paasela M, Honkanen J, Klemetti P, Vaarala O, Saarela M (2015) Altered fecal microbiota in paediatric inflammatory bowel disease. J Crohn's Colitis 9:1088-1095. https://doi.org/10.1093/ecco-jcc/jjv147

46. de Meij TGJ, de Groot EFJ, Peeters CFW, de Boer NKH, Kneepkens CMF, Eck A, Benninga MA, Savelkoul PHM, van Bodegraven AA, Budding AE (2018) Variability of core microbiota in newly diagnosed treatment-naïve paediatric inflammatory bowel disease patients. PLoS One 13:e0197649. https://doi.org/ 10.1371/journal.pone.0197649

47. Khan I, Ullah N, Zha L, Bai Y, Khan A, Zhao T, Che T, Zhang C (2019) Alteration of gut microbiota in inflammatory bowel disease (IBD): cause or consequence? IBD treatment targeting the gut microbiome. Pathogens 8:126. https://doi.org/10.3390/ pathogens 8030126

48. Gevers D, Kugathasan S, Denson LA, Vázquez-Baeza Y, Van Treuren W, Ren B, Schwager E, Knights D, Song SJ, Yassour M, 
Morgan XC, Kostic AD, Luo C, González A, McDonald D, Haberman Y, Walters T, Baker S, Rosh J, Stephens M, Heyman M, Markowitz J, Baldassano R, Griffiths A, Sylvester F, Mack D, Kim S, Crandall W, Hyams J, Huttenhower C, Knight R, Xavier RJ (2014) The treatment-naive microbiome in new-onset Crohn's disease. Cell Host Microbe 15:382-392. https://doi.org/10.1016/j. chom.2014.02.005

49. Assa A, Butcher J, Li J, Elkadri A, Sherman PM, Muise AM, Stintzi A, Mack D (2016) Mucosa-associated ileal microbiota in new-onset pediatric Crohn's disease. Inflamm Bowel Dis 22:1533-1539. https://doi.org/10.1097/mib.0000000000000776

50. Claesson MJ, Clooney AG, O'Toole PW (2017) A clinician's guide to microbiome analysis. Nat Rev Gastroenterol Hepatol 14:585595. https://doi.org/10.1038/nrgastro.2017.97

51. Michail S, Durbin M, Turner D, Griffiths AM, Mack DR, Hyams J, Leleiko N, Kenche H, Stolfi A, Wine E (2012) Alterations in the gut microbiome of children with severe ulcerative colitis. Inflamm Bowel Dis 18:1799-1808. https://doi.org/10.1002/ibd.22860

52. Iljazovic A, Roy U, Gálvez EJC, Lesker TR, Zhao B, Gronow A, Amend L, Will SE, Hofmann JD, Pils MC, Schmidt-Hohagen K, Neumann-Schaal M, Strowig T (2020) Perturbation of the gut microbiome by Prevotella spp. enhances host susceptibility to mucosal inflammation. Mucosal Immunol. https://doi.org/10.1038/ s41385-020-0296-4

53. Atarashi K (2017) Ectopic colonization of oral bacteria in the intestine drives TH1 cell induction and inflammation. Science 358:359365. https://doi.org/10.1126/science.aan 4526

54. Hyams JS, Ferry GD, Mandel FS, Gryboski JD, Kibort PM, Kirschner BS, Griffiths AM, Katz AJ, Grand RJ, Boyle JT, Michener WM, Levy JS, Lesser ML (1991) Development and validation of a pediatric Crohn's disease activity index. J Pediatr Gastroenterol Nutr 12:439

55. Lewis JD, Chuai S, Nessel L, Lichtenstein GR, Aberra FN, Ellenberg JH (2008) Use of the noninvasive components of the mayo score to assess clinical response in ulcerative colitis. Inflamm Bowel Dis 14:1660-1666. https://doi.org/10.1002/ibd. 20520

56. Turner D, Hyams J, Markowitz J, Lerer T, Mack DR, Evans J, Pfefferkorn M, Rosh J, Kay M, Crandall W, Keljo D, Otley AR, Kugathasan S, Carvalho R, Oliva-Hemker M, Langton C, Mamula P, Bousvaros A, LeLeiko N, Griffiths AM, Group PICR (2009) Appraisal of the pediatric ulcerative colitis activity index (PUCAI). Inflamm Bowel Dis 15:1218-1223. https://doi.org/10. 1002/ibd.20867

57. Peyrin-Biroulet L, Panés J, Sandborn WJ, Vermeire S, Danese S, Feagan BG, Colombel JF, Hanauer SB, Rycroft B (2016) Defining disease severity in inflammatory bowel diseases: current and future directions. Clin Gastroenterol Hepatol 14:348-354.e317. https:// doi.org/10.1016/j.cgh.2015.06.001

58. Henke MT, Kenny DJ, Cassilly CD, Vlamakis H, Xavier RJ, Clardy J (2019) Ruminococcus gnavus, a member of the human gut microbiome associated with Crohn's disease, produces an inflammatory polysaccharide. Proc Natl Acad Sci 116:12672-12677. https://doi.org/10.1073/pnas.1904099116

59. Hall AB, Yassour M, Sauk J, Garner A, Jiang X, Arthur T, Lagoudas GK, Vatanen T, Fornelos N, Wilson R, Bertha M, Cohen M, Garber J, Khalili H, Gevers D, Ananthakrishnan AN, Kugathasan S, Lander ES, Blainey P, Vlamakis H, Xavier RJ, Huttenhower C (2017) A novel Ruminococcus gnavus clade enriched in inflammatory bowel disease patients. Genome Med 9: 103. https://doi.org/10.1186/s13073-017-0490-5

60. Lewis JD, Chen EZ, Baldassano RN, Otley AR, Griffiths AM, Lee D, Bittinger K, Bailey A, Friedman ES, Hoffmann C, Albenberg L, Sinha R, Compher C, Gilroy E, Nessel L, Grant A, Chehoud C, Li H, Wu GD, Bushman FD (2015) Inflammation, antibiotics, and diet as environmental stressors of the gut microbiome in pediatric
Crohn's disease. Cell Host Microbe 18:489-500. https://doi.org/ 10.1016/j.chom.2015.09.008

61. Vangay P, Ward T, Gerber JS, Knights D (2015) Antibiotics, pediatric dysbiosis, and disease. Cell Host Microbe 17:553-564. https:// doi.org/10.1016/j.chom.2015.04.006

62. Hviid A, Svanström H, Frisch M (2011) Antibiotic use and inflammatory bowel diseases in childhood. Gut 60:49-54. https://doi.org/ 10.1136/gut.2010.219683

63. Kronman MP, Zaoutis TE, Haynes K, Feng R, Coffin SE (2012) Antibiotic exposure and IBD development among children: a population-based cohort study. Pediatrics 130:e794-e803. https:// doi.org/10.1542/peds.2011-3886

64. Ruemmele FM, Veres G, Kolho KL, Griffiths A, Levine A, Escher JC, Amil Dias J, Barabino A, Braegger CP, Bronsky J, Buderus S, Martín-de-Carpi J, De Ridder L, Fagerberg UL, Hugot JP, Kierkus J, Kolacek S, Koletzko S, Lionetti P, Miele E, Navas López VM, Paerregaard A, Russell RK, Serban DE, Shaoul R, Van Rheenen P, Veereman G, Weiss B, Wilson D, Dignass A, Eliakim A, Winter H, Turner D (2014) Consensus guidelines of ECCO/ESPGHAN on the medical management of pediatric Crohn's disease. J Crohn's Colitis 8:1179-1207. https://doi.org/10.1016/j.crohns.2014.04.005

65. Quince C, Ijaz UZ, Loman N, Eren AM, Saulnier D, Russell J, Haig SJ, Calus ST, Quick J, Barclay A, Bertz M, Blaut M, Hansen R, McGrogan P, Russell RK, Edwards CA, Gerasimidis K (2015) Extensive modulation of the fecal metagenome in children with Crohn's disease during exclusive enteral nutrition. Am J Gastroenterol 110:1718-1729; quiz 1730. https://doi.org/10.1038/ ajg.2015.357

66. Levine A, Wine E, Assa A, Sigall Boneh R, Shaoul R, Kori M, Cohen S, Peleg S, Shamaly H, On A, Millman P, Abramas L, ZivBaran T, Grant S, Abitbol G, Dunn KA, Bielawski JP, Van Limbergen J (2019) Crohn's disease exclusion diet plus partial enteral nutrition induces sustained remission in a randomized controlled trial. Gastroenterology 157:440-450.e448. https://doi.org/ 10.1053/j.gastro.2019.04.021

67. Svolos V, Hansen R, Nichols B, Quince C, Ijaz UZ, Papadopoulou RT, Edwards CA, Watson D, Alghamdi A, Brejnrod A, Ansalone C, Duncan H, Gervais L, Tayler R, Salmond J, Bolognini D, Klopfleisch R, Gaya DR, Milling S, Russell RK, Gerasimidis K (2019) Treatment of Active Crohn's disease with an ordinary food-based diet that replicates exclusive enteral nutrition. Gastroenterology 156:1354-1367.e1356. https://doi.org/10.1053/j. gastro.2018.12.002

68. Fang H, Fu L, Wang J (2018) Protocol for fecal microbiota transplantation in inflammatory bowel disease: a systematic review and meta-analysis. Biomed Res Int 2018:8941340-8941311. https:// doi.org/10.1155/2018/8941340

69. He Z, Li P, Zhu J, Cui B, Xu L, Xiang J, Zhang T, Long C, Huang G, Ji G, Nie Y, Wu K, Fan D, Zhang F (2017) Multiple fresh fecal microbiota transplants induces and maintains clinical remission in Crohn's disease complicated with inflammatory mass. Sci Rep 7: 4753. https://doi.org/10.1038/s41598-017-04984-z

70. Nishida A, Imaeda H, Ohno M, Inatomi O, Bamba S, Sugimoto M, Andoh A (2017) Efficacy and safety of single fecal microbiota transplantation for Japanese patients with mild to moderately active ulcerative colitis. J Gastroenterol 52:476-482. https://doi.org/10. 1007/s00535-016-1271-4

71. Suskind DL, Brittnacher MJ, Wahbeh G, Shaffer ML, Hayden HS, Qin X, Singh N, Damman CJ, Hager KR, Nielson H, Miller SI (2015) Fecal microbial transplant effect on clinical outcomes and fecal microbiome in active Crohn's disease. Inflamm Bowel Dis 21: 556-563. https://doi.org/10.1097/mib.0000000000000307

72. Kunde S, Pham A, Bonczyk S, Crumb T, Duba M, Conrad HJ, Cloney D, Kugathasan S (2013) Safety, tolerability, and clinical response after fecal transplantation in children and young adults 
with ulcerative colitis. J Pediatr Gastroenterol Nutr 56:597-601. https://doi.org/10.1097/MPG.0b013e318292fa0d

73. Suskind DL, Singh N, Nielson H, Wahbeh G (2015) Fecal microbial transplant via nasogastric tube for active pediatric ulcerative colitis. J Pediatr Gastroenterol Nutr 60:27-29. https://doi.org/10. 1097/mpg.0000000000000544

74. Norman JM, Handley SA, Baldridge MT, Droit L, Liu CY, Keller BC, Kambal A, Monaco CL, Zhao G, Fleshner P, Stappenbeck TS, McGovern DP, Keshavarzian A, Mutlu EA, Sauk J, Gevers D, Xavier RJ, Wang D, Parkes M, Virgin HW (2015) Disease-specific alterations in the enteric virome in inflammatory bowel disease. Cell 160:447-460. https://doi.org/10.1016/j.cell.2015.01.002

75. Fernandes MA, Verstraete SG, Phan TG, Deng X, Stekol E, LaMere B, Lynch SV, Heyman MB, Delwart E (2019) Enteric virome and bacterial microbiota in children with ulcerative colitis and Crohn disease. J Pediatr Gastroenterol Nutr 68:30-36. https:// doi.org/10.1097/mpg.0000000000002140

76. Clooney AG, Sutton TDS, Shkoporov AN, Holohan RK, Daly KM, O’Regan O, Ryan FJ, Draper LA, Plevy SE, Ross RP, Hill C (2019) Whole-virome analysis sheds light on viral dark matter in inflammatory bowel disease. Cell Host Microbe 26:764-778.e765. https:// doi.org/10.1016/j.chom.2019.10.009

77. Sokol H, Brot L, Stefanescu C, Auzolle C, Barnich N, Buisson A, Fumery M, Pariente B, Le Bourhis L, Treton X, Nancey S, Allez M, Seksik P (2020) Prominence of ileal mucosa-associated microbiota to predict postoperative endoscopic recurrence in Crohn's disease. Gut 69:462-472. https://doi.org/10.1136/gutjnl-2019-318719

78. Mukhopadhya I, Hansen R, Meharg C, Thomson JM, Russell RK, Berry SH, El-Omar EM, Hold GL (2015) The fungal microbiota of de-novo paediatric inflammatory bowel disease. Microbes Infect 17:304-310. https://doi.org/10.1016/j.micinf.2014.12.001

79. Chehoud C, Albenberg LG, Judge C, Hoffmann C, Grunberg S, Bittinger K, Baldassano RN, Lewis JD, Bushman FD, Wu GD (2015) Fungal signature in the gut microbiota of pediatric patients with inflammatory bowel disease. Inflamm Bowel Dis 21:19481956. https://doi.org/10.1097/mib.0000000000000454

80. Limon JJ, Tang J, Li D, Wolf AJ, Michelsen KS, Funari V, Gargus M, Nguyen C, Sharma P, Maymi VI, Iliev ID, Skalski JH, Brown J, Landers C, Borneman J, Braun J, Targan SR, McGovern DPB, Underhill DM (2019) Malassezia is associated with Crohn's disease and exacerbates colitis in mouse models. Cell Host Microbe 25: 377-388.e376. https://doi.org/10.1016/j.chom.2019.01.007

81. Rowland M, Fleming P, Bourke B (2009) Looking in the mouth for Crohn's disease. Inflamm Bowel Dis 16:332-337. https://doi.org/ 10.1002/ibd.20983

82. Docktor MJ, Paster BJ, Abramowicz S, Ingram J, Wang YE, Correll M, Jiang H, Cotton SL, Kokaras AS, Bousvaros A (2012) Alterations in diversity of the oral microbiome in pediatric inflammatory bowel disease. Inflamm Bowel Dis 18:935-942. https://doi. org/10.1002/ibd.21874 